\title{
Understanding relational resilience of married adults in quarantine days
}

\author{
Didem Aydogan $^{1}$ (D) $\cdot$ Ece Kara ${ }^{2}$ (D) $\cdot$ Enes Kalkan $^{3}$ (D) \\ Accepted: 9 August 2021 / Published online: 3 September 2021 \\ (C) The Author(s), under exclusive licence to Springer Science+Business Media, LLC, part of Springer Nature 2021
}

\begin{abstract}
Quarantine and isolation caused by COVID-19 pandemic revealed a new stress condition in marriage relationship. This study aimed to investigate, under quarantine and isolation days, how relational resilience in marriage is explained with their psychological distress, and mediation roles of negative and positive dyadic coping in the marriage relationship between psychological distress and relational resilience. Data of the research study was obtained via an online form two months after the announcement of the pandemic in Turkey. The participants were 386 married people (49.7\% were men, 50.3\% women) who ranged in age from 23 to 65 years $(M=37.35, S D=10.10)$. Participants were given Personal Information Form, The Relational Resilience Scale, The Dyadic Coping Inventory, Kessler Psychological Distress Scale, and Intolerance of Uncertainty Scale. Results showed that negative and positive coping have mediating influence on psychological stress of married individuals and their relational resilience during quarantine. It is seen that especially in quarantine days, positive coping strategies of married individuals, in coping with these conditions, is an important factor increasing relational resilience.
\end{abstract}

Keywords Relational resilience $\cdot$ Psychological distress $\cdot$ Intolerance of uncertainty $\cdot$ Dyadic coping $\cdot$ Covid-19 pandemic

\section{Introduction}

Throughout history, human beings have experienced a large number of viral epidemics caused by different factors like plague, malaria, cholera, H1N1 influenza a, SARS, Ebola, MERS, etc.. Coronavirus (Covid-19) spreading from Wuhan city of China at the end of 2019 is one of these diseases. The recent Covid-19 pandemic was described as a pandemic condition which has important influences on public health and mental health by World Health Organization (WHO, 2020)

Ece Kara

ecekara@sdu.edu.tr

Didem Aydogan

daydogan@adu.edu.tr

Enes Kalkan

ensklkn@gmail.com

1 Department of Psychological Counseling and Guidance, Aydın Adnan Menderes University, Aydın, Turkey

2 Department of Psychological Counseling and Guidance, Faculty of Education, Süleyman Demirel University, Isparta, Merkez, Turkey

3 Psychological Counseling and Guidance PhD Student University of Gazi, Ordu, Turkey and countries took social-physical isolation precautions and announced a quarantine condition for all people in the world in order to prevent the spread. The rapid spread potential of this pandemic, its unpredictability, mortality rates and quarantine and being under the conditions of social and physical isolation created restricting and compelling situations from many sides in living spaces of individuals. This condition leads to changes not only in mental health but also in marital relationships (Knoster et al., 2020; Pieh et al., 2020; Pietromonaco \& Overall, 2021) via stressors like partners' being together for $24 \mathrm{~h}$ within home because of quarantine, changes in time spent together, shared things and rituals, dealing with children steadily at home, and economic difficulties caused by Covid-19, etc. (Pietromonaco \& Overall, 2021; Prime et al., 2020). Under the circumstances of pandemic and crisis and stress condition caused by it, protecting the couple relationship balance system, discovery of the resources preventing disconnectedness in relationship caused by stress is necessary for a positive and healthy relationship and being a strong couple (Stanley \& Markman, 2020).

In literature, resilience is described as a process containing a positive adaptation growth after negative life events, traumatic events (Luthar et al., 2000). Resilience is an important resource providing relationship satisfaction at difficult times (Bradley \& Hojjat, 2017). Furthermore, relational resilience is 
a relational phenomenon dealt together with concepts of reinforced vulnerability, mutual emphatic, relational confidence, mutual empowerment and relational awareness stressing mutual development when there is a disconnectedness taking place as a result of stress conditions experienced in a relationship (Jordan, 2005). Relational resilience has gained widespread attention in marital research in recent years (Aydogan \& Dincer, 2020; Aydogan \& Kizildag, 2017; Venter \& Snyders, 2009).

Moreover, when negative influences of Covid-19 pandemic on mental health on an individual basis (for example, difficulty of toleration related to ambiguity of this situation and psychological distress) are taken into account it is predicted that this condition can lead married individuals to discover the ways of providing relational resilience and create influences on couples' coping approaches. In the light of these explanations, the main focus of this study is to reveal how relational resilience predicts negative and positive dyadic coping approaches of psychological distress and intolerance of uncertainty during Covid-19 Pandemic.

\section{Psychological Distress and Intolerance of Uncertainty in Quarantine Days}

During the pandemic, having to be separated from their beloved ones, the fear of losing them and their own freedom because of isolation, feeling as if losing their control, fear of getting infected, may cause individuals to experience ambiguities about the pandemic and anger bursts (Brooks et al., 2020). For example, in the research conducted by Jalloh et al. (2017) about the EBOLA epidemic, $6 \%$ of the participants were meeting the criteria for anxiety and depression and $16 \%$ were meeting diagnosis of PTSD (Post-Traumatic Stress Disorder). In another study conducted in China in order to determine the effects of Covid-19 Pandemic on mental health, it was found that the participants showed moderate levels of depressive symptoms, anxiety and high levels of stress (Salari et al., 2020; Wang et al., 2020). Additionally, it was also found that quarantine procedure creates negative mental effects like depression (Hawryluck et al., 2004; Rogers et al., 2020; Rubin \& Wessely, 2020), irritability and lack of sleep (Lee et al., 2005), acute stress (Bai et al., 2004; Ye et al., 2020) and disorders related to trauma (Wu et al., 2009) especially in groups who are under more risk (e.g., healthcare professionals). These explanations show that psychological distress, which is described as emotional damage characterized by depression and anxiety symptoms (Mirowsky \& Ross, 2002), is a significant determining factor indicating mental health of married individuals in quarantine days.

Another important factor about Covid-19 pandemic is that; the process of pandemic is quite unpredictable. Budner (1962) stated that uncertainty includes conditions or events which are unclear or are faced for the first time. Recently, uncertainties increase in economy, education, relationships and in subjects related to physical or mental health (Pietromonaco \& Overall, 2021). People who are intolerant to ambiguity assume that ambiguity is something stressful and sad and they usually think that unexpected events are negative (Robichaud \& Dugas, 2015). Studies propound that intolerance to ambiguity play an important role in development and maintenance of the anxiety condition (Dugas et al., 2005; Laugesen et al., 2003; Mahoney $\&$ McEvoy, 2012). As a matter of this fact, studies conducted on Turkish individuals have shown that the pandemic increases the risk of mental health problems (Ozdin \& Bayrak Ozdin, 2020; Yilmaz \& Eskici, 2020), and that intolerance to uncertainty has a significant direct effect on mental health (Satici et al., 2020). When studies are reviewed, it is inevitable that the uncertain and uncontrollable nature of Covid-19 will cause psychological problems (such as anxiety, stress, depression) for people who are unable to tolerate uncertainty. In researches it was found that in a marriage, couple's psychological problems like depression influence marital relationship negatively (Rehman et al., 2008; Whisman \& Uebelacker, 2009).

\section{Dyadic Coping to Relational Resilience in Marriage Relationship}

During the pandemic period, in marriages, economical concerns of one or two of the spouses, losing jobs, economic hardship, challenge of maintaining their job from home during quarantine period, parental stress caused by education and care of children, changes in relationship with close environment, problems related to health condition of family, the fear that one of the family members will be infected, and ambiguities of pandemic period create critical relationship difficulties on marital relationships (e.g., Daks et al., 2020; Lee et al., 2020a, b; Lian \& Yoon, 2020; Pietromonaco \& Overall, 2021). Furthermore quarantine may increase contact between partners and exacerbate a potential conflict (Mazza et al., 2020). In addition, when it is thought that marriages are affected by the situations they are exposed to, it is expected that spouses give varied reactions. Stress is identified as a consistent predictor of low quality and instability of close relationships in adulthood (e.g., Randall \& Bodenmann, 2009). In terms of marital relationships, Covid-19 pandemic seems to be an extra-relational stress condition as well. A stress condition arising from a relationship, on the other hand, plays a more significant role in the functionality of spouses (Bodenmann et al., 2007). That is, unexpected stress conditions could trigger some conflict and problems for the couples during the pandemic period. Moreover, when the duration of the stress is taken into account, this condition could be seen as an acute stressor (Karney et al., 2005).

Acute stress is a stress condition that may result from lifethreatening or traumatic experiences of an individual (such as natural disasters, the loss of a loved one) as is the case with Covid-19 Pandemic. Although both acute and chronic stress 
reduce relationship satisfaction, couples are more likely to have the resources to restore their relationship after acute short-term stress, but when the stress is severe, they may feel exhausted and have few resources to rely on (Karney et al., 2005). How partners react to each other under a pandemicrelated stress is expected to affect creating their couple resilience in their relationship. Stress conditions experienced in a marriage create a context in which spouses have difficulty in meeting the needs of each other and thus affect the experience which makes it difficult to evaluate the relationship of each spouse (Karney et al., 2005). Such stress conditions may cause the increase in the probability of conflict and tension by decreasing the opportunity of activities empowering the relationship (e.g., Neff \& Karney, 2017), urging spouses to react in a more aggressive manner (e.g., Bodenmann et al., 2010) and increasing probability of declining relationship satisfaction (e.g., Breitenstein et al., 2018).

However, a pandemic experience may help the improvement of marital relationships by strengthening the spouse relationships and activating the adaptive resources in a positive way. Furthermore an acute stress factor could really be positive for couples in that they rely on each other in terms of relationship resources and this experience could be an opportunity for couples' strengthening of intimacy and relationship feelings (Karney et al., 2005). Some studies reveal that relational resilience is provided by the help of strong characteristics and resources that appeared in a relationship after some negative and traumatic experiences (e.g., Aydogan \& Dincer, 2020; Aydogan \& Kizildag, 2017). The use of dyadic coping approaches could also provide partners the feeling of "weness" and remain in a more stable and satisfactory relationship (Bodenmann, 1997). This is confirmed by such findings that negative and positive dyadic coping are more effective compared to individual coping in the functionality of a relationship (e.g., Papp \& Witt, 2010).

When a life event that causes stress takes place, by using their resources so as to cope with stress, mental conditions of spouses could be changed temporarily (Karney et al., 2005). It can be deduced that in the pandemic period, spouses may rebalance their relationships and it is essential to evoke crucial resources using relationship resources which will help them move out of the crisis situation more functionally by challenging stress factors brought about by Coronavirus. In marital relationships, by the help of relational resilience, spouses not only achieve a balance after unfavorable life events, but also surpass their previous level of functionality (Venter \& Snyders, 2009). On the other hand, spouses affect each other in coping processes during stay-at-home or quarantine periods. Therefore coping with stress as a couple is to be evaluated within a multidimensional structure context as supportive, delegated, negative and joint (common) dyadic coping (Ledermann et al., 2010). Assisting of one partner to the other via problemfocused or emotion-focused reinforcement (supportive dyadic coping), undertaking responsibility to decrease the stress of the other partner (delegated dyadic coping) and taking active roles as participants in order to cope with stressful events (joint dyadic coping) are characterized by positive dyadic coping. Negative dyadic coping, on the other hand, is seen in the form of hostility, ambivalence and superficiality (Bodenmann et al., 2018; Ledermann et al., 2010). Some studies assert that coping with stress as a couple is a crucial factor in terms of defining a marital relationship quality, relationship satisfaction and stability of the relationship (Bodenmann, 2005; Bodenmann \& Cina, 2006; Ledermann et al., 2010). At the same time, a limited number of studies indicates that positive dyadic coping contributes to relational resilience of couples (Aydogan \& Ozbay, 2018). Additionally, in some studies, it was found that positive dyadic coping increases both personal and relationship satisfaction and the amount of perceived stress has an effect on relationship satisfaction (Martos et al., 2019; Rusu et al., 2020). Besides, negative dyadic coping seems to be affecting relationship satisfaction negatively (Martos et al., 2019).

\section{Current Study}

Covid-19-related stress may have an effect on individuals' mental health including fear, anxiety, depression, boredom, anger, disappointment, hyper-sensitivity, and stigmatization. (American Psychological Association (APA), 2020). In addition, it can be seen in the marriage relationship that the stress situations associated with the Covid-19 pandemic cause changes in the couple relationship processes, and even cause behaviors such as withdrawal and less supportive behavior among some couples (Pietromonaco \& Overall, 2021). On the other hand, the changes that couples experience together with the pandemic affect not only their marital relationship, but also the parent-child relationship, even family relations and family well-being as a system (Prime et al., 2020). Therefore, in the case of uncertainty and psychological stress associated with the stress because of Covid-19, revealing the dual coping approaches of married individuals on the way that provides relational resilience will open up an opportunity to comprehend family relations as a system. Relational resilience is conceptualized as stress-related growth, post-traumatic growth, development and finding benefit and the concept is regarded as a dynamic process in which couples may exhibit better adaptation outcomes in diverse periods at the same time (Gamarel \& Revenson, 2015). The aim of this study is to test mediating effects of dyadic positive and negative coping by examining direct effects of psychological stress caused by acute stress experienced during the pandemic period on relational resilience. Given the literature review above, it would not be wrong to say that there are potentially significant relationships among the variables of psychological distress, negative dyadic coping, positive dyadic coping and relational resilience. It is considered that psychological distress would 
predict relational resilience at a significant level; psychological distress would significantly predict negative dyadic coping and positive dyadic coping which would in turn significantly predict relational resilience. Consequently, we have created a model for examining the mediator role of negative and positive dyadic coping in the relationships between psychological distress and relational resilience of married individuals. Comprehending the mental states of married individuals who suffer from acute stress due to the Covid-19 pandemic and how they face and respond to the stress they experience is critical for understanding relational resilience in a marriage. This will help develop relational empowerment approaches and practices in such stressful times.

\section{Method}

\section{Participants}

The participants of this study were reached two months after the pandemic was declared in Turkey in March 2020. In this study, people in quarantine due to the Covid-19 pandemic process, living with their spouses and could answer the questionnaires online, were contacted using the purposeful sampling method. In addition to this, the participants of this study include the married individuals from different cities of Turkey, but mostly the ones living in Istanbul, Ankara, Izmir, Konya, Isparta, Gaziantep, Ordu provinces during the quarantine period. Individuals diagnosed with Covid-19 were not included in the study. The participants consisted of 386 married people ( $49.7 \%$ were men, $50.3 \%$ women) who ranged in age from 23 to 65 years $(M=37.35, S D=10.10)$. The mean duration of marriage was $9.15(S D=10.41)$ years. 269 of the participants (73.1\%) had child/children. When the number of children was investigated, it was found that 128 of the participants had (34.8\%) one child, 106 of them had two children (28.8\%), 27 of them had three children (7.3\%) and 8 participants had four children (2.2\%). Additionally, during the pandemic period, children of 134 (36.4\%) participants maintained their education at home via distance education. 238 (76.9\%) of the participants stated that the pandemic influenced their economic conditions and 23 participants, in particular, (6.3\%) stated that their economic capacity excessively decreased, 117 participants $(31.8 \%)$ stated that their financial income decreased a little. The participants of the study ranged in income from $1500(\approx \$ 173)$ to $15,000(\approx \$ 1730)$ Turkish Liras (TL, $\bar{x}$ $=6732.62$ ).

\section{Measures}

Relational Resilience Scale (RRS) The RRS developed by Aydogan and Ozbay (2015) is a self-report instrument made up of 27 items that measures a couple's recovery ability after they encounter negative life experiences. The RSS includes four subscales: actor (6 items, e.g., I try to emphasize when partner is in trouble or have hard time), partner (6 items, e.g., In times of distress and difficulty, my partner convinces me that everything will be better), union (10 items, e.g., We know that we can endure all kinds of difficulties together), and spirituality (5 items, e.g., I ask my partner to pray for everything to go well). Participants scale their responses on a 7- point $(1=$ never to $7=$ always $)$. The total score ranges from 27 to 151, with higher scores indicating more relational resilience. In this study, Cronbach's Alpha coefficient for the overall scale was .93 .

Dyadic Coping Inventory (DCI) This scale was developed originally by Bodenmann (2008) and adapted to Turkish form by Eren Kurt and Akbas (2019). The DCI is a 37-item self-report questionnaire that measures the extent to which couples actively help each other during stressful times. Each questionnaire item is scaled on "never" to "very often". This scale assesses positive dyadic coping (i.e., delegated dyadic coping, emotion focused support, problem focused support, problem focused joint dyadic coping, emotion focused joint dyadic coping) and negative dyadic coping of individuals. By means of DCI, three other separate total scores could be obtained as well; the perception of the individual about his/her own dyadic coping behaviors with stress, the perception of the individual about his/her spouse's dyadic coping behaviors with stress, and their common coping behaviors together with the spouse when they perceive a stressful condition or sub-scales can be scored separately. However in this study, negative dyadic coping (8 items, e.g., I blame my partner for not coping well enough with stress) and positive dyadic coping (19 items, e.g., I show empathy and understanding to my partner) subdimensions were used. Cronbach's Alpha coefficient was found as .81 for negative dyadic coping sub-dimension and Cronbach's Alpha coefficient was found as .91 for positive dyadic coping sub-dimension.

Intolerance of Uncertainty Scale (IUS) It was developed with the purpose of measuring the emotional and behavioral reactions individuals experience in ambiguous conditions. The English form of the scale was developed by Buhr and Dugas (2002) and its adaptation to Turkish form was made by Sari and Dag (2009). The scale consists of 26 items and scored according to 5-point-Likert type $(1=$ strongly disagree to $5=$ strongly agree). The scale consists of four sub-dimensions: $(I)$ Uncertainty leads to the inability to act (5 items, e.g. Uncertainty stops me from having a strong opinion), (II) Uncertainty is stressful and upsetting (9 items, e.g. Uncertainty makes life intolerable), (III) Negative selfevaluations of uncertainty ( 8 items, e.g. I must get away from all uncertain situations), (IV) Being uncertain about the future is unfair (4 items, e.g. I always want to know what the future 
has in store for me). Getting high scores from scale indicates that an individual's intolerance to uncertainty is high. In this study, Cronbach's Alpha coefficient for the overall scale was .95 .

Kessler Psychological Distress Scale (K10) In this study, for the assessment of psychological distress of participants during pandemic period Kessler Psychological Distress Scale (K10$P D S$ ), which is adapted into Turkish form by Altun et al. (2019), was used. The scale measures the frequency of symptoms related to mental conditions such as anger and hopelessness, etc. (Altun et al., 2019). The scale consists of 10 items (e.g. In the past 4 weeks, about how often did you feel nervous?) and the answers were scaled from $1=$ never to $5=$ always. The higher scores from the scale indicate the excess of mental distress. In this study, Cronbach's Alpha coefficient for the overall scale was .89 .

\section{Procedure and Analysis}

Prior to data collection, an approval was obtained from the Ethical Committee of the Suleyman Demirel University. The data of the study were obtained two months after the pandemic was declared, from April 29 to May 10. In the study, data collection tools were transformed into a battery, and along with informed consent forms, they were sent to individuals who were in contact with researchers, accessible, volunteer to participate in and could answer online questionnaires, and married individuals. In the study, only one of the spouses for each couple was contacted to answer measurement tools. It lasts about $15-20 \mathrm{~min}$ to respond to the questionnaires.

In the analysis of the data, SPSS 24.0 and AMOS 24.0 programs were used. In order to make an analysis from the data collected, cleaning and organizing procedures were conducted. For this purpose, by using frequency analysis, empty, lost and incorrect data were controlled. For the extreme value analysis, the data were converted to standard $\mathrm{Z}$ scores and the data belonging to the 29 participants were seen to be extreme values (except \pm 3.29 ) and removed from the data set and analysis was conducted on 368 data. In the study, before investigating the correlation analysis between variables or direct or indirect effects, it was investigated whether variables were complied with or not in accordance with normal distribution. By taking into account the fact that normality tests have a tendency to be significant for great samples, skewness and kurtosis coefficients were examined and graphics' closeness to normality rates were examined. The lowest and highest skewness values were between -.47 and .79 . The lowest and highest kurtosis values were between -.49 and .26 . Values between -1.5 and +1.5 were taken as the criteria for rankings (Tabachnick \& Fidell, 2013).

In this study, Structural Equation Model (SEM) was completed in two stages according to the suggestions of Anderson and Gerbing (1984). First, measurement model of the variables in the study were tested using confirmatory factor analysis and then a hypothetical model was tested. Measurement model and structural model were calculated via Maximum Likelihood Estimation technique. Maximum Likelihood Estimation method is evaluated as a good choice for average and big sample sizes for verification of the normality and independence assumptions (Ullman, 2015). Verification of the tested structural models was explained using Chi-square, CFI, GFI, RMSEA, and TLI values fit indices. Kline (2015) suggests reporting of at least four fit indices. In order to test the goodness of fit of the models created, $\chi 2$ / sd ratio. If this value is under 3, this means a good fit (Kline, 2015; Tabachnick \& Fidell, 2013), however, there are researchers who come to terms with this value to be below 5 (Bollen, 1989). For RMSEA $\leq .06-.08$ value shows acceptable fit indices (Hooper et al., 2008). For GFI, it shows an acceptable fit index between .08-.09 values (Greenspoon \& Saklofske, 1998). In addition, it is stated in the literature that if the CFI and TLI values are approximately .90 , it forms a criterion for the fit of the model with the data (Schermelleh-Engel et al., 2003).

\section{Results}

\section{Preliminary Analysis}

Before conducting the mediating effect analysis, we examined the inter-correlations among the variables of the study. Table 1 includes these correlations and basic descriptive statistics within the total sample. The bivariate correlations between relational resilience and intolerance of uncertainty, psychological distress, negative dyadic coping, positive dyadic coping proved to be statistically significant and it also appeared that there was a negative significant correlation between relational resilience and intolerance of uncertainty $(r=-.15, p<.01)$ and psychological distress $(r=-.31, p<.01)$, and negative dyadic coping $(r=-.39, p<.01)$. And also relational resilience was positively associated with positive dyadic coping $(r=.65, p<.01)$. Besides, married individuals' intolerance to uncertainty related to the pandemic period indicated a low correlation with relational resilience, therefore, it was excluded from the model.

\section{Measurement Model}

Confirmatory factor analysis (CFA) was performed to evaluate the measurement model. Measurement model included four latent variables (psychological distress, negative dyadic coping, positive dyadic coping, and relational resilience). An initial examination of the measurement model provided good fit indices: $\chi^{2}(318)=919.16, p<.001, \chi 2 / d f=2.89$, $\mathrm{CFI}=.88, \mathrm{GFI}=.84, \mathrm{TLI}=.87$ and $\mathrm{RMSEA}=0.07$. 
Table 1 Intercorrelations and descriptives in the total sample

\begin{tabular}{lrrlllll}
\hline & \multicolumn{1}{c}{$M$} & \multicolumn{1}{c}{$S D$} & 1 & 2 & 3 & 4 & 5 \\
\hline 1. Relational resilience & 156.14 & 19.45 & 1 & & & \\
2. Intolerance of uncertainty & 66.13 & 19.44 & $-.15^{* *}$ & 1 & & \\
3. Psychological distress & 19.82 & 6.26 & $-.31^{* *}$ & $.52^{* *}$ & 1 & & \\
4. Negative DC & 7.47 & 5.52 & $-.39^{* *}$ & $.33^{* *}$ & $.32^{* *}$ & 1 & \\
5. Positive DC & 49.39 & 11.44 & $.65^{* *}$ & $-.17^{* *}$ & $-.33^{* *}$ & $-.48^{* *}$ & 1 \\
\hline
\end{tabular}

Note. $\mathrm{DC}=$ dyadic coping

$* * p<.01$

Standardized coefficients of the measurement model gain significance at .01 levels. It is noted that $\chi 2 / \mathrm{df}$ value is good fit indices (Kline, 2015; Tabachnick \& Fidell, 2015), RMSEA and GFI values are acceptable fit indices (Greenspoon \& Saklofske, 1998; Hooper et al., 2008). Besides, it is stated that CFI and TLI values are close to acceptable values (Schermelleh-Engel et al., 2003). Based on these results it may be suggested that the measurement model substantially meets the necessary conditions in the structural model.

\section{The Structural Model}

In this study, psychological distress was used as the predictor variable; negative and positive dyadic coping as mediators; and relational resilience as a dependent variable. The latent variable of psychological distress had ten indicators (the ten items of psychological distress). The latent variable of negative dyadic coping had eight indicators (the eight items of negative dyadic coping), and positive dyadic coping was represented by emotion focused support, problem focused support, delegated dyadic coping, emotion-focused joint, problem focused joint. To test the mediating model via AMOS software program, in the first stage, the relationship between psychological distress and relational resilience was evaluated and it was found that psychological distress had a direct and significant influence on relational resilience $(\beta=-.35, p<.001)$. In the second stage of the model, mediator effects of positive and negative dyadic coping were tested. Hypothetical model that shows the mediator roles of negative and positive dyadic coping between the relationship of psychological distress and relational resilience and shown in Fig. 1 was tested by using SEM. As it is stated in direct effects in Fig. 1, psychological distress predicts negative dyadic coping directly, positively and significantly $(\beta=.41, p<.001)$; predicts positive dyadic coping directly, negatively and significantly $(\beta=-.39$, $p<.001)$. Additionally, negative dyadic coping predicts relational resilience directly, negatively and significantly $(\beta=$ $-.15, p<.01)$; and positive dyadic coping predicts relational resilience directly, positively and significantly $(\beta=.65$, $p<.001)$. On the other hand, psychological distress predicts relational resilience directly and negatively $(\beta=-.35$, $p<.001)$ but when mediator variables are included in the model, the effect between these two variables $(\beta=-.08$, $p>001)$ loses its significance. In this condition, negative and positive dyadic coping has a full mediator effect between psychological distress and relational resilience. The structural model gave a good fit to the data: $\chi 2(319)=1005.049, \mathrm{p}$ $<.001, \chi 2 / \mathrm{df}=3.15, \mathrm{GFI}=.83, \mathrm{CFI}=.86, \mathrm{TLI}=.85$, and RMSEA $=.08$.

The bootstrap estimation procedure with 1000 resamples and $95 \%$ bias-corrected confidence intervals were employed to test the significance of indirect effects. The standardized indirect effects and 95\% bias-corrected confidence intervals are presented in Table 2 . The specific indirect effect of psychological distress on relational resilience via negative dyadic coping $(\beta=.17,95 \%$ bootstrap, $\mathrm{CI}=-.28$ to $-.09, \mathrm{p}=.002)$ and the specific indirect effect via positive dyadic coping $(\beta=$ $-.26,95 \%$ bootstrap $\mathrm{CI}=-.35$ to $-.18, \mathrm{p}=.002$ ) are indicated in Table 2.

\section{Discussion}

The aim of this study is to evaluate the direct effects of psychological distress on relational resilience between married couples and the mediator effect of negative and positive dyadic coping between these two variables. Results reveal the direct negative effects of psychological distress on relational resilience that married individuals experience during quarantine days in their marriage. In addition, findings also indicate that negative and positive dyadic coping have a full mediator effect between psychological distress and relational resilience. This result reveals the significance of particularly positive dyadic coping in empowering the married individuals in terms of their relationship during the quarantine.

Measures taken in many countries to control the spread of the coronavirus seems to have a devastating effect on relationships in general and family relationships in particular (Luttik et al., 2020). Direct connections between psychological distress and relational resilience comprise a basis for the findings obtained in the model. Some studies state that quarantine causes depression and anxiety which signify a negative mental health issue (Hawryluck et al., 2004; Rogers et al., 2020; Rubin \& Wessely, 2020; Wang et al., 2020). Here, it should 


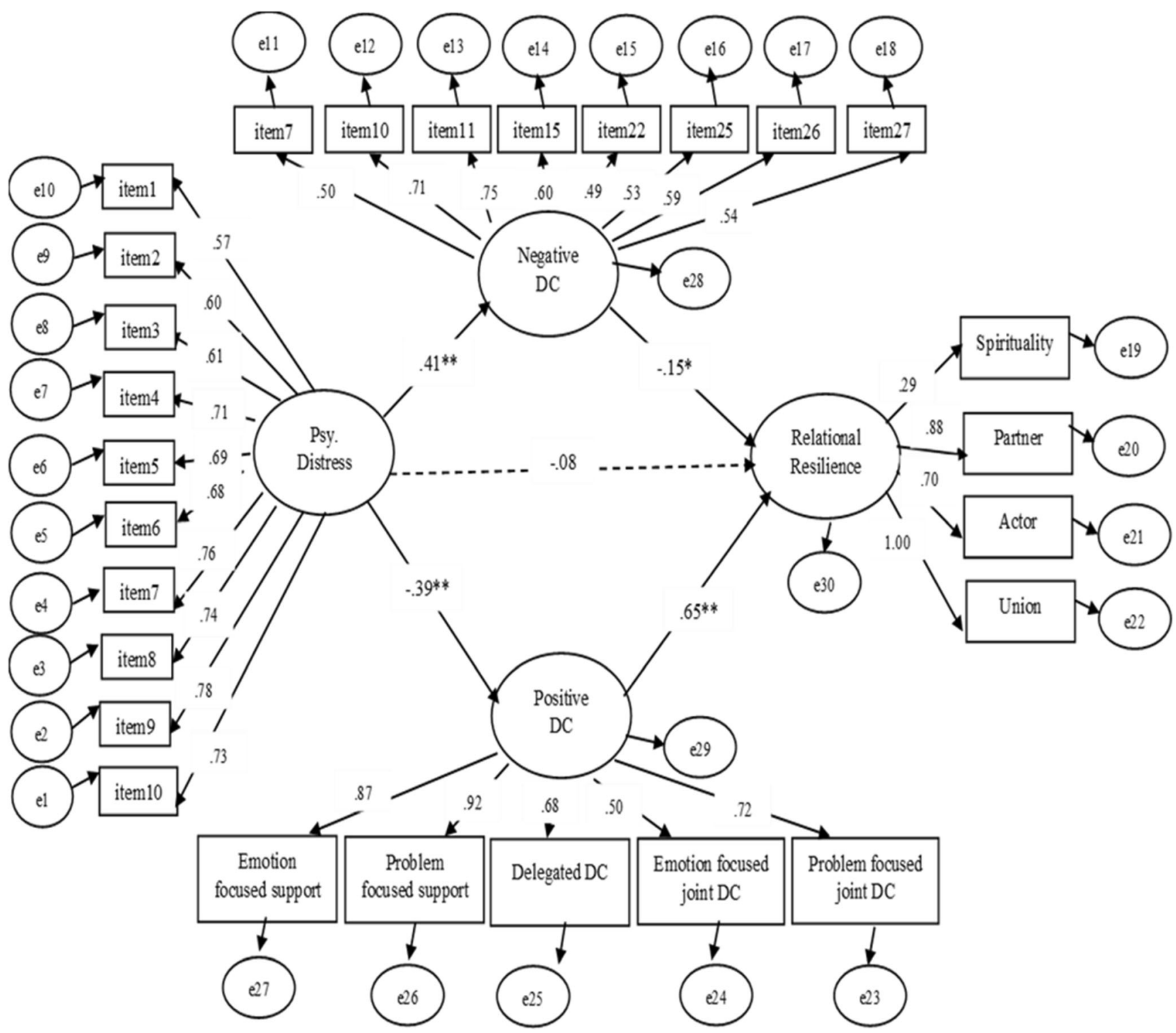

Fig. 1 The Mediation Model

be noted that there are time-dependent issues in the evaluation of obtained findings. The first quarantine procedure began on April 2, 2020 in Turkey and the data of this study was obtained in May, two months after the quarantine and that means there is approximately two months of time span after the pandemic starts. The fact that the uncertain situation related to Covid-19 Pandemic could have created a suitable basis for the emergence of psychological problems at that time is discussed in this study. Some other studies which argue that intolerance to uncertainty leads to psychological problems like
Table 2 Standardized indirect effects and $95 \%$ confidence intervals

\begin{tabular}{|c|c|c|c|c|c|}
\hline \multirow[t]{2}{*}{ Model pathways } & \multirow[t]{2}{*}{ Estimate } & \multirow[t]{2}{*}{ SE } & \multicolumn{2}{|c|}{$\mathrm{BC} \% 95 \mathrm{Cls}$} & \multirow[t]{2}{*}{$p$} \\
\hline & & & Low & $\mathrm{Up}$ & \\
\hline $\begin{array}{l}\text { Psychological } \mathrm{D} \rightarrow \text { Negative DC } \\
\rightarrow \text { Relational Resilience }\end{array}$ & -.17 & .04 & -.28 & -.09 & .002 \\
\hline $\begin{array}{l}\text { Psychological D } \rightarrow \text { Positive DC } \\
\rightarrow \text { Relational Resilience }\end{array}$ & -.26 & .04 & -.35 & -.18 & .002 \\
\hline
\end{tabular}

Note. $\mathrm{BC}=$ bias corrected $\mathrm{CI}=$ confidence interval $; \mathrm{DC}=$ Dyadic coping $* p<.01$ 
anxiety are also examined (Dugas et al., 2005; Laugesen et al., 2003). During two months of quarantine, roles and responsibilities, shared things, routines of couples underwent a change and many people found themselves in search of looking for the elements balancing the family and work lives. In such a kind of a transition process, especially, it is inescapable for couples to experience conflict at times (Mazza et al., 2020), changes in communication style and behavioral differences for each other. Changes in relationships brought about by quarantine and reflections of individual mental health to marital relationships are expected outcomes. Researchers underline that if individuals' perceptions of their own mental health are positive, their satisfaction and gratification from their marital relationships will also be positively affected (Kamp Dush et al., 2008; Kim \& McKenry, 2002; Perveen et al., 2017; Shek, 2010).

The COVID-19 pandemic is a stressor that includes acute stress, loss, and brings with it changing conditions and disruptions for couples in many areas of life (Walsh, 2020). For example, most of the participants in this study have child/ children and most of these children continue distance education. In addition, the fact that women take on more domestic roles than men in Turkish culture can create extra stress for them during the quarantine process. In addition to the acute stress caused by quarantine, such situations created an extra stress and caused changes in the roles played by couples in marriage. Acute stress-related situations can lead to negative bilateral coping by causing negative changes in the partner relationships between married couples. Negative dyadic coping; conditions like not paying attention to the stress of the partner or ridiculing partners' stress, utilizing unauthentic coping strategies or an unwilling support for the partner (Bodenmann, 2005), are crucial issues which may indeed cause temporary disconnections in the relationship. In these situations, decrease in relational resilience is something to be expected. Couples' dyadic coping competences are a way to enhance partners' ability to deal with the stress and concerns related to the epidemic (Donato et al., 2021). In literature, results reveal that dyadic coping is related to relationship satisfaction. For example, Bodenmann (2008) studies stated that both dyadic coping measures are related to relationship quality and psychological well-being. Similarly, Falconier et al. (2015) stated that both, positive dyadic coping and negative dyadic coping contributed significantly to relationship satisfaction. However, in this study, it appears that positive dyadic coping, in particular, which is one of the dyadic coping styles of married couples, makes a great contribution to explaining relational resilience. Especially in quarantine days, in terms of marriage relationship maintaining behaviors, helping daily hassles of each other, showing empathy, utilizing solidarity, helping each other in diminishing the level of stress and positive coping including the effort to cope this situation by common participation are predicted as critical resources empowering and improving relational resilience. In addition, in the study investigating the relationship between depression, anxiety and stress and relationship resilience in married individuals during the COVID-19 pandemic, it was detected that the individuals with high level of relational resilience have low levels of depression, anxiety and stress (Unver \& Guloglu, 2021). It was observed that couples who displayed positive dyadic coping in stressful times were able to reduce their distress and improve each other's psychological health (Alves et al., 2019). In some studies it is claimed that higher coping skills can help alleviate stressful situations during a pandemic (Chen \& Bonanno, 2020; Lee et al., 2020a, b) and increase relationship satisfaction in the early pandemic crisis (Williamson, 2020). Emotional contact is a factor that affects the constructiveness of family relationships individually between spouses during the quarantine (Sorokoumova et al., 2020). This result also proves valuable evidence to the empowering of marriage relationships with the way of positive dyadic coping in quarantine days caused by the pandemic. Couples' dyadic coping competences can be a way to improve partners' ability to deal with the stress and epidemic-related concern (Prime et al., 2020). Besides, in some studies, it appeared that support of spouses against coercive life conditions (Aydogan \& Kizildag, 2017) and positive dyadic coping increase relational resilience (Aydogan \& Ozbay, 2018). Likewise, in another study it is claimed that positive dyadic coping increases relationship satisfaction and quality (Papp \& Witt, 2010). This result reveals that positive dyadic coping enriches the relationships and empowers the emotional bond of couples after this acute stress making a great deal of contribution to relational resilience. From this point of view, it may be argued that a pandemic crisis can be seen as a chance or opportunity that provides the improvement of the relationship. That is, the more positive dyadic coping increases, the more relational resilience increases.

\section{Limitations and Future Research Directions}

Although this study has many strong sides, it also has some limitations. First of all, in this study, data related to dyadic stress, dyadic coping caused by the quarantine and relational resilience was obtained from one of the partners in a marriage. However, it is obvious that in face of a global pandemic, in order to understand relational resilience in marriage, studies based on the Actor-Partner Interdependence Model (APIM) and obtaining data from both of the partners in order to evaluate mutual effect are needed. Secondly, how married individuals cope with this condition based on the structural characteristics of a marriage varies in terms of reacting to the changes brought about by Covid-19 pandemic. For instance, for studies which are likely to make comparisons based on the duration of a marriage, the knowledge of having a child/children or in other words being a parent and evaluating relational resilience together with individual mental condition and dyadic stress and coping are needed. 
Thirdly, as the pandemic goes on, it is necessary to evaluate married individuals' marital stressors and personal stressors. This global pandemic was accompanied by a great number of stressors. For example, it can cause several stressful and traumatic life events like economic problems, one partner's losing his/her job, infection of a family member with Covid-19 virus or losing a family member because of Covid-19. In this study, the stress condition of the participants is limited to the quarantine at that time. Complementary studies are needed to determine risks or traumatic experiences which could be evaluated together with the stress condition experienced with the pandemic. All these results would encourage positive mental health in strengthening the relationships of couples in case of encountering such unexpected and unprecedented life events such as pandemic (for example; well-being) and would contribute to improve interventions and approaches which will increase positive dyadic coping. In the light of all these, it would not be wrong to claim that development of relational-based resilience programs would contribute to couples not only on an individual basis, but also in setting up a strong couple identity, preventing conflicts and empowering relationships.

Data Availability The data that support the findings of this study are available from the corresponding author, upon reasonable request.

\section{Declarations}

Conflict of Interest The authors declare that they have no conflict of interest.

Ethical Aproval All procedures performed in studies involving human participants were in accordance with the ethical standards of the institutional and/or national research committee and with the 1964 Helsinki declaration and its later amendments or comparable ethical standards. This study was approved by University of Süleyman Demirel, Research Ethics Committee.

Informed Consent Informed consent was obtained from all individual participants included in the study.

\section{References}

Alves, S., Milek, A., Bodenmann, G., Fonseca, A., Canavarro, M. C., \& Pereira, M. (2019). Romantic attachment, dyadic coping, and parental adjustment across the transition to parenthood. Personal Relationship, 26(2), 286-309. https://doi.org/10.1111/pere.12278

Altun, Y., Ozen, M., \& Kuloglu, M. M. (2019). Turkish adaptation of Kessler psychological distress scale: Validity and reliability study. Anatolian journal of psychiatry, 20(supplement 1), 23-31. https:// doi.org/10.5455/apd.12801

American Psychological Association (APA) (2020). "Keeping Your Distance to Stay Safe" https://www.apa.org/practice/programs/dmhi/ research-information/social-distancing Last accessed: 8 May 2020.

Anderson, J. C., \& Gerbing, D. W. (1984). The effect of sampling error on convergence, improper solutions, and goodness-of-fit indices for maximum likelihood confirmatory factor analysis. Psychometrika, 49(2), 155-173. https://doi.org/10.1007/BF02294170

Aydogan, D., \& Ozbay, Y. (2015). Development of relational resilience scale for married individuals. 13th National Congress of psychological counseling and guidance. Paper presented at the 13th National Congress of psychological counseling and guidance, Mersin, Turkey.

Aydogan, D., \& Kizildag, S. (2017). Examination of relational resilience with couple burnout and spousal support in families with a disabled child. The Family Journal, 25(4), 407-413. https://doi.org/10.1177/ 1066480717731215

Aydogan, D., \& Ozbay, Y. (2018). Mediation role of dyadic coping on parenting stress and relational resilience in couples. Marriage \& Family Review, 54(2), 128-147. https://doi.org/10.1080/01494929. 2017.1302900

Aydogan, D., \& Dincer, D. (2020). Creating resilient marriage relationships: Self-pruning and the mediation role sacrifice with satisfaction. Current Psychology, 39(2), 500-510. https://doi.org/10.1007/ s12144-019-00472-x

Bai, Y. M., Lin, C. C., Lin, C. Y., Chen, J. Y., Chue, C. M., \& Chou, P. (2004). Survey of stress reactions among health care workers involved with the SARS outbreak. Psychiatric Services, 55(9), 1055-1057. https://doi.org/10.1176/appi.ps.55.9.1055

Bodenmann, G. (1997). Dyadic coping: A systemic-transactional view of stress and coping among couples: Theory and empirical findings. European Review of Applied Psychology, 47(2), 137-140.

Bodenmann, G. (2005). Dyadic coping and its significance for marital functioning. In T. A. Revenson, K. Kayser, \& G. Bodenmann (Eds.), Couples coping with stress: Emerging perspectives on dyadic coping (pp. 33-49). American Psychological Association. https:// doi.org/10.1037/11031-002

Bodenmann, G., \& Cina, A. (2006). Stress and coping among stable-satisfied, stable-distressed and separated/divorced Swiss couples: A 5-year prospective longitudinal study. Journal of Divorce and Remarriage, 44(1-2), 71-89. https://doi.org/10.1300/J087v44n01 04

Bodenmann, G., Ledermann, T., \& Bradbury, T. N. (2007). Stress, sex, and satisfaction in marriage. Personal Relationships, 14(4), 551569. https://doi.org/10.1111/j.14756811.2007.00171.x

Bodenmann, G. (2008). Dyadic coping and the significance of this concept for prevention and therapy. Zeitschrift für Gesundheitspsychologie, 16(3), 108-111. https://doi.org/10.1026/ 0943-8149.16.3.108

Bodenmann, G., Meuwly, N., Bradbury, T. N., Gmelch, S., \& Ledermann, T. (2010). Stress, anger, and verbal aggression in intimate relationships: Moderating effects of individual and dyadic coping. Journal of Social and Personal Relationships, 27(3), 408-424. https://doi.org/10.1177/0265407510361616

Bodenmann, G., Arista, L. J., Walsh, K. J., \& Randall, A. K. (2018) Dyadic coping inventory. Encyclopedia of Couple and Family Therapy, 1-5. https://doi.org/10.1007/978-3-319-15877-8_678-1

Bollen, K. A. (1989). A new incremental fit index for general structural equation models. Sociological Methods \& Research, 17(3), 303316. https://doi.org/10.1177/0049124189017003004

Bradley, J. M., \& Hojjat, M. (2017). A model of resilience and marital satisfaction. The Journal of Social Psychology, 157(5), 588-601. https://doi.org/10.1080/00224545.2016.1254592

Breitenstein, C. J., Milek, A., Nussbeck, F. W., Davila, J., \& ve Bodenmann, G. (2018). Stress, dyadic coping, and relationship satisfaction in late adolescent couples. Journal of Social and Personal Relationships, 35(5), 770-790. https://doi.org/10.1177/ 0265407517698049

Brooks, S. K., Webster, R. K., Smith, L. E., Woodland, L., Wessely, S., Greenberg, N., \& Rubin, G. J. (2020). The psychological impact of quarantine and how to reduce it: Rapid review of the evidence. The Lancet, 395(10227), 912-920. https://doi.org/10.1016/s01406736(20)30460-8 
Budner, S. (1962). Intolerance of ambiguity as a personality variable. Journal of Personality, 30(1), 29-50. https://doi.org/10.1111/j. 1467-6494.1962.tb02303.x

Buhr, K., \& Dugas, M. J. (2002). The intolerance of uncertainty scale: Psychometric properties of the english version. Behaviour Research and Therapy, 40(8), 931-945. https://doi.org/10.1016/S00057967(01)00092-4

Daks, J. S., Peltz, J. S., \& Rogge, R. D. (2020). Psychological flexibility and inflexibility as sources of resiliency and risk during a pandemic: Modeling the cascade of COVID-19 stress on family systems with a contextual behavioral science lens. Journal of Contextual Behavioral Science, 18, 16-27. https://doi.org/10.1016/j.jcbs.2020.08.003

Donato, S., Parise, M., Pegani, A. F., Lanz, M., Regalia, C., Rosnati, R., \& Iafrate, R. (2021). Together against COVID-19 concerns: The role of the dyadic coping process for partners' psychological wellbeing during the pandemic. Frontiers in Psychology, 7, 1-9 https:// dx.doi.org/10.3389\%2Ffpsyg.2020.578395

Dugas, M. J., Marchand, A., \& Ladouceur, R. (2005). Further validation of a cognitive behavioral model of generalized anxiety disorder: Diagnostic and symptom specificity. Journal of Anxiety Disorders, 19(3), 329-343. https://doi.org/10.1016/j.janxdis.2004.02.002

Eren Kurt, İ., \& Akbas, T. (2019). Adaptation of dyadic coping inventory into Turkish. OPUS international journal of society researches, 13(19), 636-655. https://doi.org/10.26466/opus.547217

Falconier, M., Jackson, J. B., Hilpert, P., \& Bodenmann, G. (2015). Dyadic coping and relationship satisfaction: A meta-analysis. Clinical Psychology Review, 42, 28-46. https://doi.org/10.1016/j. cpr.2015.07.002

Gamarel, K. E., \& Revenson, T. A. (2015). Dyadic adaptation to chronic illness: The importance of considering context in understanding couples' resilience. In K. Skerrett \& K. Fergus (Eds.), Couple resilience: Emerging perspectives (p. 83-105). Springer Science/ Business Media. https://doi.org/10.1007/978-94-017-9909-6_5

Greenspoon, P. J., \& Saklofske, D. H. (1998). Confirmatory factor analysis of the multidimensional Students' life satisfaction scale. Personality and Individual Differences, 25(5), 965-971. https:// doi.org/10.1016/S0191-8869(98)00115-9

Hawryluck, L., Gold, W. L., Robinson, S., Pogorski, S., Galea, S., \& Styra, R. (2004). SARS control and psychological effects of quarantine. Emerging Infectious Diseases, 10(7), 1206-1212. https://doi. org/10.3201/eid1007.030703

Hooper, D., Coughlan, J., \& Mullen, M. (2008). Structural equation modeling: Guidelines for determining model fit. The electronic journal of business research Methods, 6(1), 53-60. https://doi.org/10. 21427/D7CF7R

Jalloh, M. F., Li, W., Bunnell, R. E., Ethier, K. A., O’Leary, A., Hageman, K. M., Sengeh, P., Jalloh, M. B., Morgan, O., Hersey, S., Marston, B. J., Dafae, F., \& Redd, J. T. (2017). Impact of Ebola experiences and risk perceptions on mental health in Sierra Leone, July 2015. BMJ Global Health, 3(2), 1-11. https://doi.org/10.1136/ bmjgh-2017-000471

Jordan, J. V. (2005). Relational resilience in girls. In S. Goldstein \& R. B. Brooks (Eds.), Handbook of resilience in children (pp. 79-90). Springer Science/Business Media.

Kamp Dush, C. M., Taylor, M. G., \& Kroeger, R. A. (2008). Marital happiness and psychological well-being across the life course. Family Relations, 57(2), 211-226. https://doi.org/10.1111/j.17413729.2008.00495.x

Karney, B. R., Story, L. B., \& Bradbury, T. N. (2005). Marriages in context: Interactions between chronic and acute stress among newlyweds. In T. A. Revenson, K. Kayser, \& G. Bodenmann (Eds.), Couples coping with stress: Emerging perspectives on dyadic coping (pp. 13-32). American Psychological Association. https://doi.org/10.1037/11031-001

Kim, H. K., \& McKenry, P. C. (2002). The relationship between marriage and psychological well-being: A longitudinal analysis. Journal of
Family Issues, 23(8), 885-911. https://doi.org/10.1177/ 019251302237296

Kline, R. B. (2015). Principles and practice of structural equation modeling. Guilford Press.

Knoster, K., Howard, H. A., Goodboy, A. K., \& Dillow, M. R. (2020). Spousal interference and relational turbulence during the COVID-19 pandemic. Communication Research Reports, 37, 1-9. https://doi. org/10.1080/08824096.2020.1841621

Laugesen, N., Dugas, M. J., \& Bukowski, W. M. (2003). Understanding adolescent worry: the application of a cognitive model. Journal of Abnormal Child Psychology, 31(1), 55-64. https://doi.org/10.1023/ a: 1021721332181

Ledermann, T., Bodenmann, G., Rudaz, M., \& Bradbury, T. N. (2010). Stress, communication, and marital quality in couples. Family Relations, 59(2), 195-206. https://doi.org/10.1111/j.1741-3729. 2010.00595.X

Lee, S., Chan, L. Y. Y., Chau, A. M. Y., Kwok, K. P. S., \& Kleinman, A. (2005). The experience of SARS-related stigma at Amoy gardens. Social Science and Medicine., 61(9), 2038-2046. https://doi.org/10. 1016/j.socscimed.2005.04.010

Lee, J., Chin, M., \& Sung, M. (2020a). How has COVID-19 changed families in Korea? Journal of Comparative Family Studies, 51(3-4), 301-313. https://doi.org/10.3138/jcfs.51.3-4.006

Lee, S. J., Ward, K. P., \& Rodriguez, C. (2020b, December 10). Longitudinal analysis of short term changes in relationship conflict during COVID-19: A risk and resilience perspective. https://doi.org/ 10.31234/osf.io/yqv7j.

Lee, S. J., Ward, K. P., \& Rodriguez, C. (2020, December 10). Longitudinal analysis of short term changes in relationship conflict during COVID-19: A risk and resilience perspective. Journal of Interpersonel Violence., 18, 1-23. https://doi.org/10.1177/ 08862605211006359

Lian, B., \& Yoon, S.-Y. (2020). Burdens, resilience, and mutual support: A comparative study of families in China and South Korea amid the COVID-19 pandemic. Journal of Comparative Family Studies, 51(3-4), 337-346. https://doi.org/10.3138/jcfs.51.34.009

Luthar, S. S., Cicchetti, D., \& Becker, B. (2000). The construct of resilience: A critical evaluation and guidelines for future work. Child Development, 71(3), 543-562. https://doi.org/10.1111/1467-8624.00164

Luttik, M. L. A., Mahrer-Imhof, R., Garcia-Vivar, C., Brodsgaard, A., Dieperink, K. B., Imhof, L., Ostergaard, B., Svavarsdottir, E. K., \& Konradsen, H. (2020). The COVID-19 pandemic: A family affair. Journal of Family Nursing, 26(2), 87-89. https://doi.org/10.1177/ 1074840720920883

Mahoney, A. E. J., \& McEvoy, M. P. (2012). Trait versus situationspecific intolerance of uncertainty in a clinical sample with anxiety and depressive disorders. Cognitive Behaviour Therapy, 41(1), 2639. https://doi.org/10.1080/16506073.2011.622131

Mazza, M., Marano, G., Lai, C., Janiri, L., \& Sani, G. (2020). Danger in danger: Interpersonal violence during COVID-19 quarantine. Psychiatry Research, 289, 113046. https://doi.org/10.1016/j. psychres.2020.113046

Martos, T., Szabó, E., Koren, R., \& Sallay, V. (2019). Dyadic coping in personal projects of romantic partners: Assessment and associations with relationship satisfaction. Current Psychology, 40(6), 1-14. https://doi.org/10.1007/s12144-019-00222-z

Mirowsky, J., \& Ross, C. E. (2002). Measurement for a human science. Journal of Health and Social Behavior, 43(2), 152-170. https://doi. org/10.2307/3090194

Neff, L. A., \& Karney, B. R. (2017). Acknowledging the elephant in the room: How stressful environmental contexts shape relationship dynamics. Current Opinion in Psychology, 13, 107-110. https://doi. org/10.1016/j.copsyc.2016.05.013

Ozdin, S., \& Bayrak Ozdin, Ș. (2020). Levels and predictors of anxiety, depression and health anxiety during COVID-19 pandemic in Turkish society: The importance of gender. The International 
Journal of Social Psychiatry, 66(5), 504-511. https://doi.org/10. 1177/0020764020927051

Papp, L. M., \& Witt, N. L. (2010). Romantic partners' individual coping strategies and dyadic coping: Implications for relationship functioning. Journal of Family Psychology, 24(5), 551-559. https://doi.org/ 10.1037/a0020836

Perveen, A., Kee, P., Taufiq, I., Khan, W., Rehman, A. U., Khan, I. A., \& Morgul, E. (2017). Marital satisfaction and mental health among working community in Malaysia. Global journal for research analysis, 6(8), 598-600. https://doi.org/10.36106/gjra

Pieh, C., ÓRourke, T., Budimir, S., \& Probst, T. (2020). Relationship quality and mental health during COVID-19 lockdown. PLoS One, 15(9), e0238906. https://doi.org/10.1371/journal.pone.0238906

Pietromonaco, P. R., \& Overall, N. C. (2021). Applying relationship science to evaluate how the COVID-19 pandemic may impact couples' relationships. American Psychologist, 76(3), 438-450. https:// doi.org/10.1037/amp0000714

Prime, H., Wade, M., \& Browne, D. T. (2020). Risk and resilience in family well-being during the COVID-19 pandemic. American Psychologist, 75(5), 631-643. https://doi.org/10.1037/amp0000660

Randall, A. K., \& Bodenmann, G. (2009). The role of stress on close relationships and marital satisfaction. Clinical Psychology Review, 29(2), 105-115. https://doi.org/10.1016/j.cpr.2008.10.004

Rehman, U. S., Gollan, J., \& Mortimer, A. R. (2008). The marital context of depression: Research, limitations, and new directions. Clinical Psychology Review, 28(2), 179-198. https://doi.org/10.1016/j.cpr. 2007.04.007

Robichaud, M., \& Dugas, M. J. (2015). The generalized anxiety disorder workbook: a comprehensive CBT guide for coping with uncertainty, worry, and fear. New Harbinger Publications.

Rogers, J. P., Chesney, E., Oliver, D., Pollak, T. A., McGuire, P., FusarPoli, P., Zandi, M. S., Lewis, G., \& David, A. S. (2020). Psychiatric and neuropsychiatric presentations associated with severe coronavirus infections: A systematic review and meta-analysis with comparison to the COVID-19 pandemic. The lancet Psychiatry, 7(7), 611627. https://doi.org/10.1016/S2215-0366(20)30203-0

Rubin, G. J., \& Wessely, S. (2020). The psychological effects of quarantining a city. BMJ (Clinical research ed.), 368, m313. https://doi.org/10.1136/bmj.m313

Rusu, P. P., Nussbeck, F. W., Leuchtmann, L., \& Bodenmann, G. (2020). Stress, dyadic coping, and relationship satisfaction: A longitudinal study disentangling timely stable from yearly fluctuations. PLoS One, 15(4), 1-23. https://doi.org/10.1371/journal.pone.0231133

Salari, N., Hosseinian, N. A., Jalali, R., Vaisi-Raygani, A., Rasoulpoor, S., Mohammadi, M., Rasoulpoor, S., \& Khaledi-Paveh, B. (2020). Prevalence of stress, anxiety, depression among the general population during the COVID-19 pandemic: A systematic review and meta-analysis. Globalization and Health, 16(57), 1-11. https://doi.org/ 10.1186/s12992-020-00589-w

Sari, S., \& Dag, İ. (2009). Problem solving style, hopelessness, helplessness and hopelessness as the predictors of psychopathology assessed by MMPI-2. Anatolian Journal of Psychiatry, 10(3), 261-270 http:// www.ihsandag.gen.tr/index_dosyalar/SariveDag2009.pdf

Satici, B., Saricali, M., Satici, S. A., and Griffiths, M. D. (2020). Intolerance of uncertainty and mental wellbeing: Serial mediation by rumination and fear of COVID 19. International journal of mental health and addiction, 15,1-12. Advance online publication.https:// doi.org/10.1007/s11469-020-00305-0

Schermelleh-Engel, K., Moosbrugger, H., \& Müller, H. (2003). Evaluating the fit of structural equation models: Test of significance and descriptive goodness-of-fit measures. Methods of Psychological Research Online, 8(2), 23-74.

Shek, D. T. L. (2010). Marital quality and psychological well-being of married adults in a Chinese context. The Journal of Genetic
Psychology: Research and Theory on Human Development, 156(1), 45-56. https://doi.org/10.1080/00221325.1995.9914805

Sorokoumova, E. A., Matveeva, E. N., Cherdymova, E. I., Puchkova, E. B., Temnova, L. V., Chernyshova, E. L., \& Ivanov, D. V. (2020). Features of communication between spouses during long-term forced self-isolation as a factor of constructive marital relationships. EurAsian Journal of BioSciences, 14, 3863-3868.

Stanley, S. M., \& Markman, H. J. (2020). Helping couples in the shadow of COVID 19. Family Process, 59(3), 937-955. https://doi.org/10. 1111/famp. 12575

Tabachnick, B. G., \& Fidell, L. S. (2013). Using multivariate statistics (sixth ed.). Pearson.

Ullman, J.B. (2015). Structural equation modeling. Using multivariate statistics (6th ed., pp. 681-785). Pearson Press.

Unver, D., \& Guloglu, B. (2021). The investigation of depression, anxiety, stress and relational resilience in married individuals throughout Covid-19 outbreak. Eurasian Journal of Researches in Social and Economics., 2(8), 517-531 https://dergipark.org.tr/tr/pub/asead/ issue/62195/894022

Venter, N., \& Snyders, R. (2009). Resilience in intimate relationships. New Voices in Psychology., 5(1), 63-85.

Walsh, F. (2020). Loss and resilience in the time of Covid-19: Meaning making, hope and transcendence. Family Process, 59(3), 898-911. https://doi.org/10.1111/famp.12588

Wang, C., Pan, R., Wan, X., Tan, Y., Xu, L., Ho, C. S., \& Ho, R. C. (2020). Immediate psychological responses and associated factors during the initial stage of the 2019 Corona virus disease (COVID19) epidemic among the general population in China. International Journal of Environmental Research and Public Health, 17(5), 1729. https://doi.org/10.3390/ijerph17051729

Whisman, M. A., \& Uebelacker, L. A. (2009). Prospective associations between marital discord and depressive symptoms in middle-aged and older adults. Psychology and Aging, 24(1), 184-189. https://doi. org/10.1037/a0014759

Williamson, H. C. (2020). Early effects of the COVID-19 pandemic on relationship satisfaction and attribution. Psychological Science, 31(12), 1479-1487. https://doi.org/10.1177/0956797620972688

World Health Organization. (2020). Mental health and psychosocial considerations during the COVID-19 outbreak, 18 march 2020. World Health Organization Retrieved from https://apps.who.int/iris/handle/ $10665 / 331490$

Wu, P., Fang, Y., Guan, Z., Fan, B., Kong, J., Yao, Z., Liu, X., Fuller, C. J., Susser, E., Lu, J., \& Hoven, C. W. (2009). The psychological impact of the SARS epidemic on hospital employees in China: Exposure, risk perception, and altruistic acceptance of risk. Canadian Journal of Psychiatry, 54(5), 302-311. https://doi.org/ 10.1177/070674370905400504

World Health Organization. (2020). Mental health and psychosocial considerations during the COVID-19 outbreak, 18 March 2020. World Health Organization. Retrieved from https://apps.who.int/iris/ handle/10665/331490

Ye, Z., Yang, X., Zeng, C., Wang, Y., Shen, Z., Li, X., \& Lin, D. (2020). Resilience, social support, and coping as mediators between COVID-19-related stressful experiences and acute stress disorder among college students in China. Applied Psychology. Health and Well-Being, 12(4), 1074-1094. https://doi.org/10.1111/aphw.12211

Yilmaz, S., \& Eskici, G. (2020). Evaluation of emotional (depression) and behavioral (nutritional, physical activity, sleep) status of Turkish adults during the Covid-19 pandemic period. Public Health Nutrition, 24, 1-20. https://doi.org/10.1017/S136898002000498X

Publisher's Note Springer Nature remains neutral with regard to jurisdictional claims in published maps and institutional affiliations. 